Volume 16 - Número 1 - jan/jul de 2021

\title{
LEITURA DE REPORTAGEM DE SITES EM LÍNGUA INGLESA: UMA PROPOSTA PARA O DESENVOLVIMENTO DE HABILIDADES LEITORAS
}

\author{
READING NEWS REPORTS IN ENGLISH LANGUAGE SITES: A PROPOSAL FOR \\ THE DEVELOPMENT OF READING SKILLS
}

\author{
Renata Carolina e Silva Rocha Pinto ${ }^{1}$
}

\begin{abstract}
RESUMO: A habilidade leitora em língua inglesa é frequentemente exigida no acesso a diversos conteúdos da internet, a materiais ou manuais técnicos e a muitos ambientes de estudo e trabalho. A Base Nacional Comum Curricular (BNCC), sensível a essas necessidades, prescreve o desenvolvimento de habilidades de leitura em Língua Inglesa, incluindo a leitura de textos multissemióticos, em ambientes virtuais. A pesquisa aqui relatada teve como objetivo geral oferecer subsídios para o professor de Língua Inglesa contribuir para o desenvolvimento das habilidades leitoras de alunos do $9^{\circ}$ ano e do Ensino Médio. Especificamente, objetivou investigar propostas sobre desenvolvimento de habilidades de leitura em língua estrangeira e articulá-las a outros pressupostos teóricos para organizar procedimentos de leitura de reportagens veiculadas em sites de veículos de comunicação. Teoricamente, fundamenta-se na concepção sociocognitiva de leitura, em pressupostos teóricos para o ensino de leitura em língua inglesa, no conceito bakhtiniano de gênero discursivo e em estudos sobre reportagem. Metodologicamente, é uma pesquisa de caráter qualitativo, de cunho bibliográfico. Como resultados, apresentam-se um quadro de procedimentos gerais e de estratégias de leitura, a partir da fundamentação teórica, e exemplificação de uma atividade de leitura de reportagem veiculada na internet. Conclui-se que o quadro proposto contribui para uma pedagogia de leitura em língua estrangeira a partir de textos autênticos, multissemióticos, sobre temas de interesse dos alunos. Permite, ainda, contemplar as habilidades de leitura prescritas pela BNCC para o ensino de língua inglesa.
\end{abstract}

PALAVRAS-CHAVE: Ensino de Língua Inglesa. Leitura. Notícia. Reportagem. Internet. BNCC.

ABSTRACT: English reading skills are often required when accessing a range of Internet content, technical materials or manuals and for several study and work environments. The National Common Curricular Base (BNCC), sensitive to these needs, determines the development of English language reading skills, including the reading of multisemiotic texts, in online environments. The general goal of this research was offering subsidies for the English language teacher to contribute to the development of reading skills of 9th grade and high school students. Specifically, it aimed to investigate proposals on the development of reading skills in a foreign language and articulate them with other theoretical assumptions in order to organize procedures for reading reports published on online mainstream media. Theoretically, it is based on the socio-cognitive conception of reading, on theoretical assumptions for the teaching of reading in the English language, on the Bakhtinian concept of discursive genre and on studies on news reports. Methodologically, it is a qualitative research, of bibliographic nature. As a result, a framework of general procedures and reading strategies is presented, based on the theoretical foundation, and an example of a report reading activity broadcast on the internet. It is concluded that the proposed framework contributes to a pedagogy of reading in a foreign language based on authentic, multisemiotic texts on topics of interest to students. It also makes it possible to tackle the reading skills determined by the BNCC for English teaching.

KEYWORDS: English Language Teaching. Reading. News. News Report. Internet. BNCC.

\section{Considerações iniciais}

Este artigo é um recorte de minha Dissertação de Mestrado em Linguística Aplicada (ROCHA-PINTO, 2020), cujo tema é o desenvolvimento de habilidades de leitura em língua inglesa de estudantes do $9^{\circ}$ ano e do Ensino Médio. Por necessidade de delimitar o escopo da pesquisa, a habilidade leitora foi escolhida porque a leitura em inglês é frequentemente

\footnotetext{
${ }^{1}$ Mestre em Linguística Aplicada pela Universidade de Taubaté - UNITAU (2020). Especialista em Ensinode Língua Inglesa -UNITAU (2014). Graduada em Letras Português/ Inglês e respectivas literaturas pela Universidade de Taubaté - UNITAU (2015).E-mail: re.csrp@gmail.com
} 
Volume 16 - Número 1 - jan/jul de 2021

exigida no acesso a diversos conteúdos presentes na internet, em materiais ou manuais técnicos e em muitos ambientes de trabalho. A necessidade de leitura em contextos de trabalho e no meio digital também é destacada na Base Nacional Comum Curricular - BNCC (BRASIL, 2018), que prescreve o desenvolvimento de estratégias de compreensão para que o estudante possa interagir nas diversas esferas da sociedade.

Outro motivo que legitima a necessidade de se desenvolverem atividades voltadas a uma pedagogia da leitura em língua estrangeira é a imprescindibilidade de melhorar o ensino do segundo idioma na escola pública. Pesquisas apontam para a falta de conhecimento da língua inglesa por jovens brasileiros (BRITISH COUNCIL, 2015). A isso, soma-se a falta de motivação dos alunos no ensino regular e professores com pouco domínio da disciplina, como mostram as pesquisas de Gervai (2018), Pontes e Davel (2016), entre outras.

Nesse cenário de dificuldades no ensino de língua inglesa, pesquisas apontam inadequações nos livros didáticos. Tílio (2012) constatou, em duas coleções, textos claramente escritos para fins pedagógicos, desconectados de contextos reais de uso, e atividades que exigiam operações mentais simples. Falkenbach e Fontana (2016) analisaram dois livros didáticos e concluíram que, apesar de ambos anunciarem uma abordagem sociointeracionista da linguagem, apenas um deles desenvolveu atividades que atendiam a esse propósito. Esses são alguns exemplos de como materiais didáticos têm falhado, principalmente em proporcionar encontros com a língua em situações reais de uso.

A pesquisa relatada neste artigo tem como objetivo investigar propostas sobre desenvolvimento de habilidades de leitura em língua estrangeira e articulá-las a outros pressupostos teóricos para organizar procedimentos de leitura de reportagens veiculadas em sites de veículos de comunicação de credibilidade. Assim, espera-se colaborar com subsídios para que o professor de língua inglesa possa contribuir para o desenvolvimento das habilidades leitoras dos alunos do $9^{\circ}$ ano do Ensino Fundamental e do Ensino Médio com o uso de textos autênticos, escolhidos de acordo com o provável interesse dos alunos pelos fatos ou temas de repercussão no momento das aulas. Além disso, incluem-se ambientes virtuais no ensino de língua inglesa, com a possibilidade de exploração de recursos da multiplicidade de linguagem (multissemiose) desses ambientes. Os procedimentos de leitura propostos contemplam as habilidades de leitura prescritas pela BNCC para o ensino de língua inglesa.

Teoricamente, baseia-se na concepção de leitura como um evento cognitivo e sóciohistórico, realizado a partir de exemplares de gêneros discursivos, de acordo com a perspectiva bakhtiniana de linguagem. Como a proposta de procedimentos de leitura desta pesquisa está relacionada ao gênero jornalístico reportagem, abordam-se também características desse gênero a partir de estudos da área da Comunicação Social. A metodologia é a de uma pesquisa de caráter qualitativo, de cunho bibliográfico, que busca, nos dizeres de Lakatos e Marconi (1991, p. 183), não a "mera repetição do que já foi dito ou escrito sobre certo assunto, mas propicia o exame de um tema sob novo enfoque ou abordagem, chegando a conclusões inovadoras". Do exame das propostas para o ensino de leitura em língua inglesa e articulação com os demais pressupostos teóricos, resultou um quadro de procedimentos gerais e de estratégias de leitura de reportagem veiculada na internet, e a exemplificação de atividades de leitura, como expõem as seções a seguir.

\section{Concepção bakhtiniana de linguagem e de gênero discursivo}

A concepção enunciativo-discursiva de linguagem desenvolvida pelo Círculo de Bakhtin destaca que a atuação humana, em todos os campos, se dá pelo uso da linguagem. Em situações reais de comunicação, o emprego da linguagem ocorre na forma de enunciados concretos, denominados por Bakhtin (2011) de gêneros do discurso (discursivos). Para o 
desenvolvimento da proposta desta pesquisa, o gênero discursivo reportagem em ambiente virtual deve ser descrito em seus principais aspectos. Para tanto, seguem alguns pressupostos teóricos a partir de Bakhtin (2011) e de outros estudiosos e comentadores de sua obra.

Bakhtin (2011) explica que a língua é utilizada na forma de enunciados concretos, exemplares de gêneros discursivos orais ou escritos, elaborados pelos indivíduos que atuam em determinada esfera da comunicação, seja ela religiosa, jornalística, escolar, literária ou outra. Os gêneros caracterizam-se por certa estabilidade em três elementos constitutivos fundamentais: conteúdo temático, estilo e construção composicional.

Comentando o conceito de gênero discursivo, Machado (2005) afirma que Bakhtin abre espaço para a heteroglossia, conceito que diz respeito às manifestações de linguagem que não se restringem à palavra, mas abrangem toda a formação discursiva guiada pelos meios de comunicação em massa e pelas mídias digitais. Nesse sentido, entende-se que um gênero discursivo pode ser composto por imagens, destaques de diagramação, recursos gráficos diversos, entre outros aspectos da comunicação verbal impressa. Essa propriedade tem sido denominada de multimodalidade (DIONÍSIO, 2005) ou multissemiose (ROJO; BARBOSA, 2015; BRASIL, 2018). Dionísio (2005) esclarece que sempre há pelo menos dois modos de representação nos enunciados. No caso do gênero discursivo escrito, a palavra e algum outro aspecto visual. Nos meios de comunicação em massa são possíveis diversos arranjos visuais. No caso de gêneros discursivos orais, ocorrem a palavra (o verbal) e entonação, gestos, acentos valorativos. Dessa forma, a multimodalidade é um traço constitutivo dos gêneros discursivos e deve ser incorporada às práticas de leitura, ainda segundo essa autora.

Bakhtin (2011) aponta a dinamicidade dos gêneros discursivos. Na medida em que os diversos campos da atividade humana - familiar, jornalístico, religioso, tecnológico, midiático, entre outros - se desenvolvem, os gêneros discursivos utilizados podem se modificar e até deixar de ser usados. Novos gêneros emergem para atender às necessidades de comunicação dos indivíduos. O gênero discursivo reportagem é um exemplo de gênero que, em sua modalidade escrita, foi se adequando às possibilidades gráficas do jornalismo. Atualmente, também é produzido em jornais disponibilizados na internet e, nesse meio digital, adquiriu alguns novos elementos composicionais.

As práticas discursivas na perspectiva bakhtiniana pressupõem interação e uma postura ativa de resposta. Machado (2005) explica que essa interação não está relacionada à noção de ouvinte passivo diante do discurso do outro, mas à noção de enunciador e coenunciador que estabelece juízo de valor, se posiciona perante o texto (concordando, discordando, rejeitando, completando o enunciado ou, ainda, baseando-se nele para produzir outros enunciados ou ações). Por isso, Bakhtin (2011, p. 296) explica que "Todo enunciado concreto é um elo na cadeia da comunicação discursiva de um determinado campo". Assim, os enunciados produzidos em uma dada esfera da sociedade são compreendidos ativamente pelos diversos interlocutores e geram algum tipo de reação, de resposta, em um sentido amplo. Essa dimensão dialógica da linguagem insere os enunciados numa cadeia discursiva e os relaciona com textos presentes, passados e futuros. Isso confere uma natureza complexa ao enunciado, o que impossibilita seu estudo por um viés meramente linguístico (BRAIT, 2016).

Fiorin (2011) comenta que Bakhtin estuda as situações concretas e a interação dos indivíduos, pois defende que os indivíduos se constituem na relação com o outro, a partir da contraposição de valores. Essa constituição do indivíduo pela propriedade dialógica da linguagem, explica Fiorin (2011), é central na obra de Bakhtin, para quem todo o diálogo se orienta para o discurso dos outros e somente o Adão mítico não teria seu discurso atravessado pelo discurso dos outros. Quando um enunciador produz o discurso, ele leva em consideração os discursos dos outros, que o antecederam e que o sucederão, e, sendo assim, uma palavra sempre perpassará a palavra do outro. Para o filósofo russo, somente pela linguagem de 
outrem é possível acessar a realidade. $\mathrm{Na}$ interação discursiva, o indivíduo absorve o enunciado alheio, incorpora-o ao seu próprio enunciado e amplia a percepção de realidade.

Essas propriedades da linguagem concebida na perspectiva enunciativo-discursiva justificam que os gêneros discursivos tenham sido propostos como objetos privilegiados de ensino desde o final dos anos 90 do século XX e se mantêm na BNCC (BRASIL, 2018), explica Lopes-Rossi (2018). Para que a leitura em sala de aula se desenvolva, essa autora recomenda que sejam consideradas as características específicas do gênero discursivo alvo da leitura, as relações dialógicas estabelecidas pelos textos lidos e a manifestação da atitude responsiva do estudante em relação aos textos. Esse processo complexo pode ser viabilizado em um contexto de leitura como um evento cognitivo e sócio-histórico e a partir de certos procedimentos organizadores da atividade leitora, como expõem as seções a seguir.

\section{A reportagem no ambiente digital}

A reportagem é um gênero da esfera jornalística, veiculado por diversas mídias, como jornais impressos, televisionados, rádio, internet, entre outros. Sua função básica é informar com um texto mais extenso e circunstanciado, sobre fatos ou temas atuais de interesse de seu público-alvo. O jornalista deve se basear em fontes fidedignas de informação e em pesquisa criteriosa (COIMBRA, 2004; LAGE, 2001; NOBLAT, 2008). O leitor crítico deve perceber quando há exagero das informações ou deturpação da realidade, uma vez que, no jornalismo, as informações são transformadas em produtos de consumo (SCALZO, 2003).

Martins Filho (1997) aponta que a reportagem é a própria essência do jornal. Apura as razões e os efeitos, debate temas e desdobra os aspectos mais importantes. As reportagens longas são divididas, no jornalismo impresso, em retrancas e boxes, que são divisões do texto para facilitar o acompanhamento da leitura. O lead é o parágrafo introdutório, recurso importante para a construção dos textos, pois apresenta a soma dos detalhes do fato e deve responder às perguntas quem, o que, onde, quando, como e por quê. Mesmo que o leitor não acompanhe o jornalista até o final, ele obterá o mínimo de informação necessária para manterse informado sobre o assunto. Outros elementos composicionais importantes são título e subtítulo. O primeiro, em poucas palavras, dá a ideia geral sobre o que se trata o texto; o segundo resume as informações principais. Diferenciam-se do corpo do texto com espaços e letras maiores. (O GLOBO, 2003; MARTINS FILHO, 1997; SCALZO, 2003).

A composição não verbal da reportagem também é muito importante na sua constituição como gênero discursivo. Sempre apresenta fotos, ilustrações, infográficos, efeitos diversos de diagramação e cores. Faria (2001) explica que fotografias passam credibilidade a respeito da informação, apesar de retratarem apenas uma parcela da realidade. Para a autora, os leitores devem analisar os elementos formais que traduzem visualmente a informação (planos, linhas, formas básicas e suas combinações, ritmo, movimento e luz) e o lugar que ocupam no corpo do texto. As fotos podem sugerir interpretações não explicitadas no texto. A legenda das fotos também precisa ser observada, pois pode conter apenas uma descrição simples ou evidenciar o posicionamento do jornal. O leitor crítico, explica Lopes-Rossi (2018), analisa imagens em diálogo com o texto e com o contexto.

Rojo e Barbosa (2015) afirmam que a abordagem bakhtiniana de gêneros discursivos ainda é potente para analisar gêneros da esfera digital, que permitem acesso a outros textos e ampliam as possibilidades instantâneas de interação e de resposta do leitor, em manifestação clara dos mecanismos dialógicos desses enunciados. No entanto, advertem as autoras, há muito mais canais de informação disponíveis e, nesse sentido, o leitor precisa estar atento à qualidade das informações. As autoras destacam a necessidade de trabalho com a multiplicidade de linguagens (multissemioses), de cultura e de discussão sobre os modos de 
fazer jornalismo atualmente. Assim, é imprescindível que os alunos desenvolvam também habilidades de curadoria dos textos, conhecendo e identificando características de credibilidade dos canais (como fonte de informação, indicação de autoria, entre outros).

Reportagens veiculadas pela internet adquiriram características multissemióticas mais complexas do que as das reportagens impressas. Para esta pesquisa, foram consultados os web sites noticiosos The Guardian e BBC News (britânicos), The Washington Post, The New York Times, CNN e Huffington Post (americanos) e a versão internacional online do jornal Folha de S. Paulo, que publica notícias em inglês. Todos são de livre acesso. A partir de um corpus de 4 reportagens - Long before Zoom, British soldiers used technology to stay connected during World War II (The Washington Post), Researchers created a test to determine which masks are the least effective (CNN), The Best Ways To Clean And Disinfect Your Phone During The Coronavirus Outbreak (Huffington Post) e Meet the model agency fighting body fascism (The guardian) - foram observadas algumas características que interessam para o trabalho de leitura em sala de aula.

A reportagem veiculada online mantém as características da reportagem impressa. Apresenta título, subtítulo, fotografia, legenda da fotografia e informação sobre a seção temática do jornal no qual essa reportagem está inserida. $O$ texto mantém o padrão e o estilo do jornalismo impresso. A esses componentes conhecidos, somam-se outros decorrentes das condições de produção e circulação do gênero no meio digital. O primeiro ponto interessante de ser notado é a presença de um anúncio publicitário fixo no topo da página. É importante que o leitor distinga o que é informação jornalística do que é elemento de marketing.

A imagem que ilustra e informa sobre o texto pode também ser um hiperlink, que direciona o leitor para outra página, permitindo acessar outras informações sobre o mesmo tema. O recurso do zoom pode ser regulado para proporcionar maior conforto durante a leitura. A cada mudança no zoom a quantidade de informação exibida na tela se altera, e para ver o restante do conteúdo é necessário 'rolar' a página. Essa é uma característica de todas as páginas da internet. Enquanto na mídia impressa o leitor move os olhos e vira as páginas, na leitura digital o leitor deve usar o mouse para rolar a notícia quando lendo por um computador ou os dedos quando lendo por um dispositivo móvel, como celular ou tablet. Há fotografias que podem ser visualizadas em tamanho maior e em formato de apresentação de slides.

Duas das reportagens selecionadas apresentam um vídeo relacionado. Ao abrir a reportagem, o vídeo inicia automaticamente, sem que o leitor precise executar ação alguma. Logo abaixo do vídeo, há outros sobre diferentes assuntos, se o leitor não os pausar, continuam sendo reproduzidos ininterruptamente. Somente após o vídeo, o texto principal começa. Ao rolá-lo para baixo, o vídeo que estava no início da reportagem se torna uma janela flutuante ( escrever comentários sobre a reportagem. Ao clicar no ícone, o leitor também pode ler os comentários de outras pessoas e postar os seus. Para a sala de aula, fica a sugestão de trabalhar também com a produção escrita de comentários sobre reportagens.

Foi observada, também, a possibilidade de o vídeo não integrar o conteúdo, mas ser relacionado ao contexto. Parece necessário que os alunos saibam identificar essas características a fim de distinguirem se elas são parte integrante do texto e complementam seu conteúdo ou se são apenas relacionadas ao tópico geral. A identificação desses elementos semióticos faz parte da formação de um leitor proficiente de reportagens veiculados online.

Anúncios publicitários podem aparecem entre os diferentes trechos do texto, mas não sinalizam divisão de assunto, subtítulo ou o término da reportagem. Observou-se um caso de uma capa de uma revista estampada em uma das reportagens. É importante que, na leitura da reportagem em ambiente digital, o leitor reconheça que há outros gêneros inseridos na reportagem, bem como perceba os efeitos de sentido que essas inserções provocam. 
Volume 16 - Número 1 - jan/jul de 2021

Essas características da reportagem em ambiente digital possibilitam escolha de conteúdo temático que possa interessar aos alunos e discussões sobre diversidade, inclusão e outros temas pertinentes ao $9^{\circ}$ ano e ao Ensino Médio. Para a viabilização dessa prática em sala de aula, apresenta-se a abordagem de leitura que pressupõe a construção de sentidos por um leitor que situa o texto no contexto sócio-histórico, interage e dialoga com ele.

\section{A leitura como um evento cognitivo e sócio-histórico}

Lopes-Rossi (2018) comenta que não há um modelo teórico que aborde especificamente a leitura de gêneros discursivos em sala de aula, mas que uma concepção sociocognitiva pode ser articulada muito bem com a perspectiva bakhtiniana. Isso porque os conhecimentos prévios do leitor, incluindo conhecimentos sobre o gênero discursivo e o evento comunicativo que ele realiza, entre muitos outros conhecimentos, são essenciais para as inferências do leitor e sua compreensão dialógica do texto.

Essa concepção considera a compreensão como um processo muito além da decodificação das palavras e estruturas. Sousa e Gabriel (2009) comentam que leitura engloba vários processamentos cognitivos, tais como acessar o conhecimento lexical para decodificação e interpretação das palavras, mobilizar conhecimentos de mundo, modificar os próprios conhecimentos. Compreender é produzir inferências, explica Vargas (2005), e isso depende de um leitor ativo na interação com o texto. Marcuschi (1996, p. 74) define inferência como uma "atividade cognitiva que realizamos quando reunimos algumas informações conhecidas para chegarmos a outras informações novas". Esse processo de elaboração de inferências depende de conhecimentos do leitor, seu contexto cognitivo, suas crenças, circunstâncias de recepção do texto e conhecimentos sobre o gênero discursivo.

Visto que a linguagem é mediadora entre a relação dos indivíduos com o mundo real, Koch (2005) explica que, em uma abordagem sociocognitiva, o texto passa a ser o lugar de interação entre os sujeitos, que, dialogicamente, mobilizam seus saberes para a compreensão de novos enunciados e, como os conhecimentos não são estáticos, os leitores também se reconstroem dentro das cenas enunciativas. Marcuschi (2008) entende o texto como um evento comunicativo, sempre em processo de elaboração, estando a compreensão sempre sujeita à influência do momento sócio-histórico. $\mathrm{O}$ autor afirma que o texto deve ser tomado como um evento comunicativo no qual as ações linguísticas, sociais e cognitivas interagem. Nesse sentido, o leitor se encontra inserido na realidade e precisa operar sobre os conteúdos inseridos no texto e com os contextos socioculturais. Os diferentes contextos nos quais os leitores se inserem explicarão a multiplicidade de discursos que o constituem como sujeito.

Para que os leitores consigam realizar os processos cognitivos necessários para compreender o texto, é fundamental que tenham objetivos de leitura e um comportamento estratégico. Nesse sentido, os autores mencionados concordam que estratégias metacognitivas, isto é, realizadas como procedimentos conscientes, devem ser ensinadas na escola para o desenvolvimento das habilidades leitoras. Uma grande pesquisa realizada por Viana et al (2017) em todas as escolas de uma rede de ensino público de uma cidade de Portugal, com os $3^{\circ}, 4^{\circ}, 5^{\circ}$ e $6^{\circ}$ anos do ensino básico, mostrou o ótimo resultado do ensino explícito de estratégias nas habilidades leitoras em língua materna, apenas para citar dados de pesquisa mais recentes. A importância da instrução explícita de estratégias de leitura em língua estrangeira também é preconizada por pesquisadores há algumas décadas.

Articulando propriedades da linguagem e o conceito bakhtiniano de gênero discursivos com a abordagem sociocognitiva de leitura, Lopes-Rossi (2018) expõe sua proposta de sequência de atividades de leitura, já colocada em prática em muitos contextos de ensino, que se organiza em quatro procedimentos de leitura:1) Acionamento de conhecimentos sobre o 
Volume 16 - Número 1 - jan/jul de 2021

gênero discursivo; 2) leitura rápida dos elementos mais destacados para identificação do tema do texto (se possível) e formulação de objetivos para a leitura do texto completo; 3) leitura inferencial mais complexa, com enfoque em partes específicas do texto e características constitutivas do gênero; 4) apreciação crítica da abordagem do tema e percepção das relações dialógicas constitutivas do enunciado.

$\mathrm{Na}$ sequência, mostra-se como esses procedimentos podem ser desenvolvidos com o foco na leitura em língua estrangeira.

\section{Desenvolvimento de habilidades de leitura em língua estrangeira}

Investigar propostas sobre desenvolvimento de habilidades de leitura em língua estrangeira é o primeiro objetivo específico desta pesquisa. Foram analisados 9 trabalhos sobre o tema, de 17 autores. Diversos autores discorrem sobre a distinção dos termos "estratégia" e "habilidade". Para esta pesquisa, cabe apontar que, de maneira geral, estratégias metacognitivas podem ser definidas como ações empregadas conscientemente pelos leitores a fim de compreender um texto, de solucionar problemas de compreensão, no intuito de construir o sentido do que lê. Com instrução explícita e com a prática, uma estratégia metacognitiva pode se tornar uma habilidade (CARREL, 1998; SINGHAL, 2001; AFFLERBACH; PEARSON; PARIS, 2008). Uma habilidade, portanto, é uma estratégia já internalizada e automatizada no processo da leitura. Corresponde também ao termo "estratégia cognitiva". Estratégias metacognitivas de leitura proporcionam aumento de atenção, memória, capacidade de aprendizagem, uma vez que os alunos aprendem a organizar as informações extraídas do texto e a prestar atenção no processo de leitura.

Os vários autores consultados sobre ensino de estratégias de leitura no ensino de língua estrangeira relacionam e discutem extensivamente diversas estratégias, coincidindo em muitos aspectos. Dada a limitação de espaço deste artigo, suas propostas são resumidas no quadro 1 a seguir. Destaca-se o papel do professor na instrução metacognitiva, guiando os alunos e "construindo andaimes" para eles (scaffolding). Além disso, alguns autores acrescentam as estratégias motivacionais, no sentido de que o aluno se sentirá mais estimulado a realizar uma tarefa de leitura quando conhece as ações necessárias para que a compreensão aconteça. Assim, a instrução explícita de estratégias metacognitivas acrescenta a camada motivacional ao aprendizado (SINGHAL 2001; MOKHTARI; REICHARD, 2002).

Os trabalhos analisados não apresentam uma lista de estratégias a serem abordadas, à exceção de Watkins (2017). De maneira geral. As estratégias que compõem o quadro 1 a seguir foram citadas ao longo dos artigos e/ou capítulos de livros para ilustrar, exemplificar e fornecer orientações sobre como o trabalho de leitura estratégica pode ser desenvolvido em sala de aula. Essas estratégias encontram respaldo nos estudos cognitivos sobre leitura, detalhadamente expostos pelos autores, e em pesquisas empíricas, em alguns casos.

Segue o quadro resumo das propostas de dezesseis autores para o desenvolvimento da leitura em alunos menos proficientes.

Quadro 1: Estratégias de leitura para o ensino de língua estrangeira

\begin{tabular}{|l|l|l|l|l|l|l|l|l|}
\hline Autores & $\begin{array}{l}\text { Carrel } \\
(1998)\end{array}$ & $\begin{array}{l}\text { Singhal } \\
(2001)\end{array}$ & $\begin{array}{l}\text { Mokhtari } \\
\text { e } \\
\text { Reichard } \\
(2008)\end{array}$ & $\begin{array}{l}\text { Santorum } \\
\text { e Scherer } \\
(2008)\end{array}$ & $\begin{array}{l}\text { Afflerback, } \\
\text { Pearson e } \\
\text { Paris } \\
(2008)\end{array}$ & $\begin{array}{l}\text { McKewon } \\
\text { Beck e } \\
\text { Blake } \\
(2009)\end{array}$ & $\begin{array}{l}\text { Donini, } \\
\text { Platero, } \\
\text { Weighel } \\
(2010)\end{array}$ & $\begin{array}{l}\text { Watkins } \\
(2017)\end{array}$ \\
\hline Skimming & $\mathrm{X}$ & & $\mathrm{X}$ & & & & $\mathrm{X}$ & $\mathrm{X}$ \\
\hline Scanning & $\mathrm{X}$ & $\mathrm{X}$ & & & & & $\mathrm{X}$ & $\mathrm{X}$ \\
\hline $\begin{array}{l}\text { Advinhações } \\
\text { Contextuais/ }\end{array}$ & $\mathrm{X}$ & $\mathrm{X}$ & & $\mathrm{X}$ & & $\mathrm{X}$ & $\begin{array}{l}\text { X } \\
\text { brainstorm }\end{array}$ & $\mathrm{X}$ \\
\hline
\end{tabular}


Volume 16 - Número 1 - jan/jul de 2021

\begin{tabular}{|c|c|c|c|c|c|c|c|c|}
\hline $\begin{array}{l}\text { Previsões/ } \\
\text { Formulação de } \\
\text { hipóteses }\end{array}$ & & & & & & & ing & \\
\hline $\begin{array}{l}\text { Identificação da } \\
\text { Ideia principal/ } \\
\text { central }\end{array}$ & $\mathrm{X}$ & & & & & & $\mathrm{X}$ & $\bar{X}$ \\
\hline $\begin{array}{l}\text { Uso de Palavras } \\
\text { Cognatas }\end{array}$ & $\mathrm{X}$ & & & & & & & \\
\hline $\begin{array}{l}\text { Reconheciment } \\
\text { o/análise da } \\
\text { estrutura } \\
\text { Textual }\end{array}$ & $\mathrm{X}$ & $\mathrm{X}$ & & $\mathrm{X}$ & & & & $X$ \\
\hline Decodificação & $\mathrm{X}$ & & & & & & & \\
\hline Reletitura & & & & & & & & $\mathrm{X}$ \\
\hline $\begin{array}{l}\text { Elaboração de } \\
\text { Resumos }\end{array}$ & & $\mathrm{X}$ & $\mathrm{X}$ & & $\mathrm{X}$ & $\mathrm{X}$ & & $\mathrm{X}$ \\
\hline $\begin{array}{l}\text { Geração de } \\
\text { perguntas / } \\
\text { objetivos de } \\
\text { leitura } \\
\end{array}$ & $\mathrm{X}$ & $\mathrm{X}$ & $X$ & $X$ & $X$ & $\mathrm{X}$ & & $X$ \\
\hline $\begin{array}{l}\text { (Aumentar) } \\
\text { Concentração }\end{array}$ & & $\mathrm{X}$ & $\mathrm{X}$ & & & & & \\
\hline $\begin{array}{l}\text { Alteração da } \\
\text { Velocidade de } \\
\text { Leitura }\end{array}$ & & $\mathrm{X}$ & $\mathrm{X}$ & & & & & \\
\hline $\begin{array}{l}\text { Utilização de } \\
\text { Pistas } \\
\text { contextuais }\end{array}$ & & $\mathrm{X}$ & $X$ & & & & & \\
\hline $\begin{array}{l}\text { Fazer } \\
\text { Inferências }\end{array}$ & $\mathrm{X}$ & $\mathrm{X}$ & & $X$ & $\mathrm{X}$ & & & $\mathrm{X}$ \\
\hline $\begin{array}{l}\text { Busca de } \\
\text { conhecimento } \\
\text { prévio }\end{array}$ & & & $\mathrm{X}$ & & & $\mathrm{X}($ & $\mathrm{X}$ & $\bar{X}$ \\
\hline $\begin{array}{l}\text { Uso de recursos } \\
\text { de gráficos }\end{array}$ & & $\mathrm{X}$ & $\mathrm{X}$ & & & $\mathrm{X}$ & & $\bar{X}$ \\
\hline $\begin{array}{l}\text { Elaboração de } \\
\text { paráfrase }\end{array}$ & & $X$ & $X$ & & & & & \\
\hline $\begin{array}{l}\text { Relacionamento } \\
\text { do conteúdo do } \\
\text { texto com } \\
\text { experiências } \\
\text { pré-existentes }\end{array}$ & & & $X$ & $\mathrm{X}$ & & & $X$ & $X$ \\
\hline
\end{tabular}

Fonte: Elaborado para esta pesquisa, a partir dos autores mencionados.

Donini, Platero e Weighel (2010), Scrivener (2011), Wallace (2001) e Watkins (2017) sugerem organizar as atividades de leitura em três etapas: pré leitura, leitura e pós leitura. A BNCC (BRASIL, 2018) também sugere tal organização das atividades de leitura.

Esse documento destaca que os eixos leitura, produção escrita, oralidade e análise linguística devem estar interligados às práticas sociais. Assume que a língua é híbrida, polifônica e multimodal; deve ser compreendida como um todo. Apresenta o conteúdo organizado por habilidades agrupadas em unidades temáticas e apresentadas para cada um dos eixos e séries do segundo ciclo do Ensino Fundamental. Apesar de a BNCC (BRASIL, 2018) afirmar que os eixos devem ser trabalhados em conjunto, a descrição das diferentes habilidades não parece deixar explícito para o professor como ele pode integrá-las. $\mathrm{Na}$ impossibilidade de reproduzir aqui, por falta de espaço, todas as habilidades do eixo leitura prescritas por esse documento, fica o registro de que são 17 para o Ensino Fundamental, indo 
desde à decodificação até a análise, critica e comparação de textos de diferentes perspectivas apresentadas sobre um mesmo assunto. Incluem-se informações veiculadas em ambientes virtuais e a multissemiose dos textos.

Para o Ensino Médio, o documento aponta que devem ser consolidadas e aprofundadas as competências e habilidades desenvolvidas no Ensino Fundamental. A Língua Inglesa deve ser compreendida a partir de seu caráter global e dos diversos usos. Busca-se "expandir os repertórios linguísticos, multissemióticos e culturais dos estudantes" (BRASIL, 2018, p. 485), desenvolver consciência e reflexão crítica quanto ao uso do idioma na sociedade contemporânea, além de problematizar os motivos pelos quais se tornou língua de uso global.

Rojo (2015) alerta que, para a discussão teórica não ser apenas sedutora, é necessário conjugá-la às práticas pedagógicas em sala de aula. Dessa forma, articulando os pressupostos teóricos e as propostas dos vários autores, esta pesquisa apresenta o quadro 2, a seguir, para organizar atividades de leitura de reportagens em ambiente digital, em inglês. Esse quadro não pode ser encarado pelo professor como uma sequência rígida, mas sim como um apoio à compreensão leitora do aluno, uma sequência provável, com toda possibilidade de alteração nos momentos em que houver necessidade. As habilidades prescritas pela BNCC (BRASIL, 2018) ficam contempladas por esses procedimentos e estratégias.

Quadro 2: Procedimentos e estratégias de leitura para notícias e reportagens de sites em inglês.

\begin{tabular}{|c|c|c|}
\hline $\begin{array}{l}\text { Procedimentos gerais } \\
\text { propostos por Lopes-Rossi } \\
(2018)\end{array}$ & \multicolumn{2}{|c|}{$\begin{array}{l}\text { Aspectos específicos da leitura de textos da internet que podem ser } \\
\text { explorados nos procedimentos gerais, por meio de estratégias de leitura. }\end{array}$} \\
\hline \multicolumn{3}{|l|}{ Pré-leitura } \\
\hline $\begin{array}{l}\text { 1) Acionamento e ampliação } \\
\text { de conhecimento prévio } \\
\text { sobre o gênero discursivo. } \\
\text { Procedimento realizado } \\
\text { oralmente com os alunos. }\end{array}$ & $\begin{array}{l}\text { - Escolha de temática } \\
\text { interessante/ relevante aos } \\
\text { alunos } \\
\text { - Referência ao conhecimento } \\
\text { prévio linguístico e temático } \\
\text { do aluno e experiências pré- } \\
\text { existentes }\end{array}$ & $\begin{array}{l}\text { - características do texto na internet } \\
\text { (fonte, propagandas, o que é parte da } \\
\text { notícia ou reportagem e o que não é). } \\
\text { - hiperlinks presentes no texto (hiperlinks } \\
\text { no corpo do texto ou imagens que são } \\
\text { hiperlinks). } \\
\text { - presença de vídeos que são ou não parte } \\
\text { integrante do gênero. }\end{array}$ \\
\hline $\begin{array}{l}\text { 2) Leitura rápida dos } \\
\text { elementos mais destacados } \\
\text { para identificação do tema do } \\
\text { texto (se possível) e } \\
\text { formulação de objetivos para } \\
\text { a leitura do texto completo. } \\
\text { Ao final dessa etapa, uma } \\
\text { conversa para aferir o que os } \\
\text { alunos fizeram. }\end{array}$ & $\begin{array}{l}\text { - Skimming } \\
\text { - Identificação de palavras } \\
\text { cognatas e de palavras } \\
\text { conhecidas } \\
\text { - Utilização de Pistas } \\
\text { contextuais } \\
\text { - Uso de recursos gráficos para } \\
\text { melhorar a compreensão } \\
\text { - Geração de perguntas / } \\
\text { objetivos de leitura detalhada } \\
\text { - inferências }\end{array}$ & $\begin{array}{l}\text { - Possibilidade de clicar nos links para } \\
\text { visualizar e verificar do que o hiperlink } \\
\text { trata. } \\
\text { - Possibilidade de discutir qual a } \\
\text { contribuição deles para o assunto da } \\
\text { notícia. } \\
\text { - Possibilidade de explorar os demais } \\
\text { recursos em áudio e vídeo (as imagens } \\
\text { podem contribuir para a formulação de } \\
\text { hipóteses sobre o assunto do texto } \\
\text { principal). }\end{array}$ \\
\hline \multicolumn{3}{|l|}{ Leitura } \\
\hline $\begin{array}{l}\text { 3) Leitura inferencial mais } \\
\text { complexa, com enfoque em } \\
\text { partes específicas do texto e } \\
\text { características constitutivas } \\
\text { do gênero discursivo. } \\
\text { Ao final, conversa com os } \\
\text { alunos. }\end{array}$ & $\begin{array}{l}\text { - Scanning } \\
\text { - Utilização de pistas } \\
\text { contextuais } \\
\text { - Identificação da Ideia } \\
\text { principal/ central } \\
\text { - Inferências }\end{array}$ & $\begin{array}{l}\text { - As características da reportagem ou } \\
\text { notícia online com os recursos } \\
\text { multimidiáticos e hiperlinks previamente } \\
\text { acessados. } \\
\text { - No caso da notícia, a leitura do lead. }\end{array}$ \\
\hline \multicolumn{2}{|l|}{ Pós-leitura } & $\bullet$ \\
\hline $\begin{array}{l}\text { 4) Apreciação crítica da } \\
\text { abordagem do tema e } \\
\text { percepção de relações }\end{array}$ & $\begin{array}{l}\text { - Avaliação do conteúdo do } \\
\text { texto } \\
\text { - Inferências }\end{array}$ & $\begin{array}{l}\text { - Apreciação das relações estabelecidas } \\
\text { com os hiperlinks das notícias e } \\
\text { reportagens, com as sugestões e com as }\end{array}$ \\
\hline
\end{tabular}


Volume 16 - Número 1 - jan/jul de 2021

dialógicas que o exemplar

do gênero discursivo

estabelece.

Fonte: Elaborado para esta pesquisa, a partir dos autores mencionados.

6 Atividades de leitura de uma reportagem veiculada pela internet Long before Zoom, British soldiers used technology to stay connected during World War II, 10/08/2020

A fim de exemplificar os procedimentos descritos no quadro 2, da seção aterior, será apresentado um exemplo de uma reportagem do jornal The Washignton Post. Uma das características multissemióticas da reportagem em ambiente digital é o vídeo que está relacionado com a reportagem logo abaixo do subtítulo.

A figura 13, a seguir, refere-se à primeira tela de visualização da reportagem.

Figura 1: Imagem retirada da tela da reportagem "Long before Zoom: British soldiers used technology to stay connected during World War II'. Acessada em 10/08/2020.

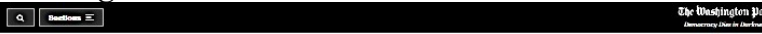
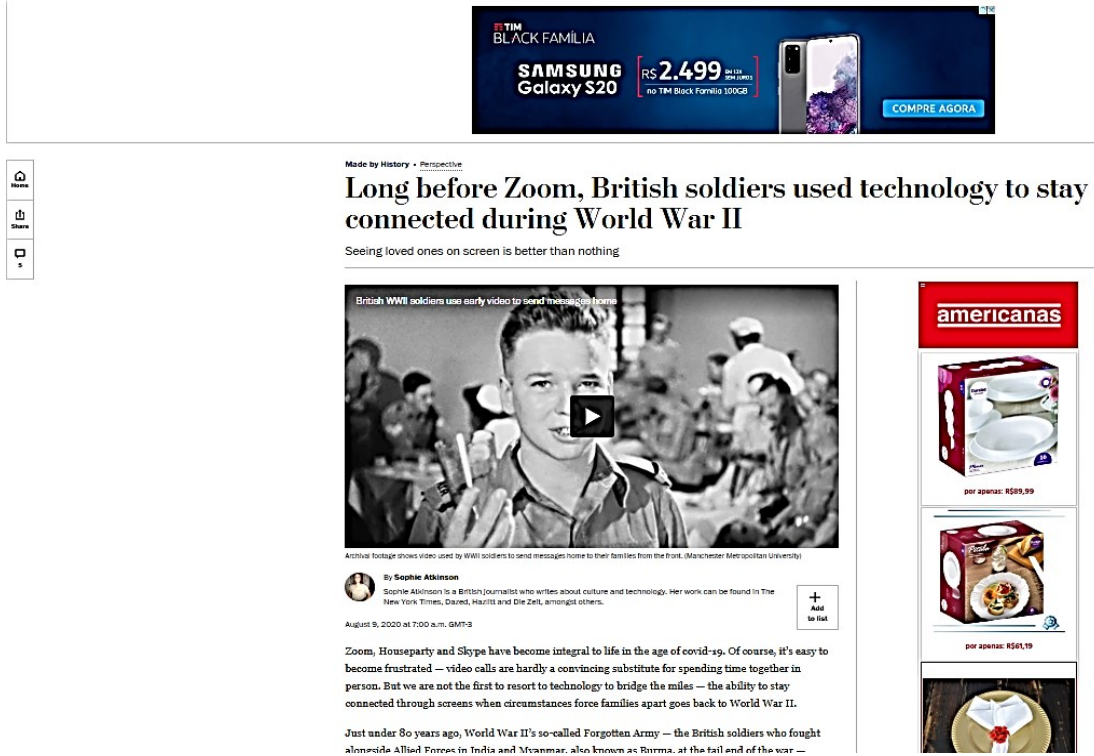

Fonte: $\quad$ https://www.washingtonpost.com/outlook/2020/08/09/long-before-zoom-british-soldiers-usedtechnology-stay-connected-during-wwii/

Além do vídeo, outro recurso apresentado é a possibilidade de escrever comentários sobre a reportagem, recurso disponível ao clicar no ícone do canto superior esquerdo da tela. O leitor também pode ler os comentários de outras pessoas e postar seus comentários.

Essa reportagem trata de fatos históricos na Inglaterra, durante a Segunda Guerra Mundial. A informação sobre a comunicação dos soldados britânicos com a família por intermédio de gravações em vídeos não representaria nenhuma novidade se não fosse a situação de pandemia na data de publicação dessa reportagem. Em função do isolamento social, medida preventiva para que o Coronavírus (COVID-19) não seja transmitido rapidamente, as pessoas passaram a fazer videochamadas, oportunizando o debate acerca desse tema e a discussão do fato histórico relatado.

O quadro 3 a seguir é uma reprodução do quadro 2, que resume os procedimentos gerais e estratégias sugeridos para organizar a leitura de reportagens veiculadas pela internet, acrescido de sugestões específicas para essa reportagem selecionada. Isso se encontra na quarta coluna do quadro. São sugestões, uma exemplificação do que pode ser feito, sem restrições à possibilidade de o professor substituir ou acrescentar procedimentos, de acordo com as necessidades de seus alunos ou a direção que os comentários e discussões tomam no 
Volume 16 - Número 1 - jan/jul de 2021

decorrer da aula. Importa tem em mente que, de acordo com a fundamentação teórica, é possível traçar um percurso básico para orientar uma pedagogia de leitura em sala de aula, passando por níveis de leitura que contribuirão para que os alunos construam uma compreensão mais crítica do texto. No caso dessa reportagem, sem desconsiderar os recursos multissemióticos da página.

Quadro 3- Atividades de leitura da reportagem "Long before Zoom: British soldiers used technology to stay connected during World War II"."

\begin{tabular}{|c|c|c|c|}
\hline $\begin{array}{l}\text { Procedimentos } \\
\text { gerais } \\
\text { propostos por } \\
\text { Lopes-Rossi } \\
(2018)\end{array}$ & \multicolumn{2}{|c|}{$\begin{array}{l}\text { Aspectos específicos da leitura de textos da } \\
\text { internet que podem ser explorados nos } \\
\text { procedimentos gerais, por meio de estratégias de } \\
\text { leitura. }\end{array}$} & $\begin{array}{l}\text { Atividades de Leitura da Reportagem } \\
\text { Brazil's modernist palaces could soon be } \\
\text { disfigured by anti-drone systems". }\end{array}$ \\
\hline \multicolumn{4}{|l|}{ Pré-leitura } \\
\hline $\begin{array}{l}\text { 1) Acionamento } \\
\text { e ampliação de } \\
\text { conhecimento } \\
\text { prévio sobre o } \\
\text { gênero } \\
\text { discursivo. } \\
\text { Procedimento } \\
\text { realizado } \\
\text { oralmente com } \\
\text { os alunos. }\end{array}$ & $\begin{array}{l}\text { - Escolha de } \\
\text { temática } \\
\text { interessante/ } \\
\text { relevante aos } \\
\text { alunos } \\
\text { - Referência ao } \\
\text { conhecimento } \\
\text { prévio linguístico } \\
\text { e temático do } \\
\text { aluno e } \\
\text { experiências pré- } \\
\text { existentes }\end{array}$ & $\begin{array}{l}\text { - características do texto } \\
\text { na internet (fonte, } \\
\text { propagandas, o que é } \\
\text { parte da notícia ou } \\
\text { reportagem e o que não } \\
\text { é). } \\
\text { - hiperlinks presentes no } \\
\text { texto (hiperlinks no } \\
\text { corpo do texto ou } \\
\text { imagens que são } \\
\text { hiperlinks). } \\
\text { - presença de vídeos que } \\
\text { são ou não parte } \\
\text { integrante do gênero. }\end{array}$ & $\begin{array}{l}\text { 1 - Discuta as questões } \\
\text { Você usa o Zoom? Quais outros recursos } \\
\text { de comunicação por vídeo você utiliza? } \\
\text { Em quais contextos as pessoas já } \\
\text { utilizaram vídeos para se comunicar? } \\
2 \text { - Você conhece reportagem? Quais são } \\
\text { as características da reportagem? } \\
3 \text { - Abra a reportagem e observe os } \\
\text { elementos que a compõem, quais são } \\
\text { partes integrantes do texto e quais não } \\
\text { são? O vídeo que precede o texto } \\
\text { principal é parte integrante? E a seção de } \\
\text { comentários? } \\
4 \text { - Assista ao vídeo e tente inferir quem } \\
\text { são as pessoas, em qual contexto aquele } \\
\text { vídeo foi gravado? }\end{array}$ \\
\hline $\begin{array}{l}\text { 2) Leitura rápida } \\
\text { dos elementos } \\
\text { mais destacados } \\
\text { para } \\
\text { identificação do } \\
\text { tema do texto } \\
\text { (se possível) e } \\
\text { formulação de } \\
\text { objetivos para a } \\
\text { leitura do texto } \\
\text { completo. } \\
\text { Ao final dessa } \\
\text { etapa, uma } \\
\text { conversa para } \\
\text { aferir o que os } \\
\text { alunos fizeram. }\end{array}$ & $\begin{array}{l}\text { - Skimming } \\
\text { - Identificação de } \\
\text { palavras cognatas } \\
\text { e de palavras } \\
\text { conhecidas. } \\
\text { - Utilização de } \\
\text { Pistas contextuais } \\
\text { - Uso de recursos } \\
\text { gráficos para } \\
\text { melhorar a } \\
\text { compreensão } \\
\text { - Geração de } \\
\text { perguntas / } \\
\text { objetivos de } \\
\text { leitura detalhada } \\
\text { - inferências }\end{array}$ & $\begin{array}{l}\text { - Possibilidade de clicar } \\
\text { nos links para visualizar } \\
\text { e verificar do que o } \\
\text { hiperlink trata. } \\
\text { - Possibilidade de discutir } \\
\text { qual a contribuição deles } \\
\text { para o assunto da } \\
\text { notícia. } \\
\text { - Possibilidade de } \\
\text { explorar os demais } \\
\text { recursos em áudio e } \\
\text { vídeo (as imagens } \\
\text { podem contribuir para a } \\
\text { formulação de hipóteses } \\
\text { sobre o assunto do texto } \\
\text { principal). }\end{array}$ & $\begin{array}{l}\text { 1 - Após ter assistido ao vídeo, quais } \\
\text { informações você gostaria de encontrar } \\
\text { no texto? 2- Leia o texto rapidamente e } \\
\text { localize onde há informações sobre o } \\
\text { contexto o vídeo que abre a notícia foi } \\
\text { gravado. Seus objetivos de leitura } \\
\text { referem-se a encontrar as partes do texto } \\
\text { onde há essas informações e tentar } \\
\text { compreendê-las, ainda que não } \\
\text { completamente, usando: } \\
\text { - palavras cognatas } \\
\text { - pistas contextuais sobre partes em que } \\
\text { se encontram as informações que você } \\
\text { procura } \\
\text { - recursos gráficos que ajudam a } \\
\text { melhorar sua compreensão geral. Ainda } \\
\text { não é necessário ter compreendido } \\
\text { tudo, detalhadamente. }\end{array}$ \\
\hline \multicolumn{4}{|l|}{ Leitura } \\
\hline $\begin{array}{l}\text { 3) Leitura } \\
\text { inferencial mais } \\
\text { complexa, com } \\
\text { enfoque em } \\
\text { partes } \\
\text { específicas do } \\
\text { texto e } \\
\text { características }\end{array}$ & $\begin{array}{l}\text { - Scanning } \\
\text { - Utilização de } \\
\text { pistas contextuais } \\
\text { - Identificação da } \\
\text { Ideia principal/ } \\
\text { central } \\
\text { - Inferências }\end{array}$ & $\begin{array}{l}\text { - As características da } \\
\text { reportagem ou notícia } \\
\text { online com os recursos } \\
\text { multimidiáticos e } \\
\text { hiperlinks previamente } \\
\text { acessados. } \\
\text { - No caso da notícia, a } \\
\text { leitura do lead. }\end{array}$ & $\begin{array}{l}\text { Leia a reportagem e busque } \\
\text { compreender melhor alguma parte } \\
\text { que você selecionou. Também } \\
\text { responda as perguntas: } \\
\text { - Where are soldiers from? } \\
\text { - Which war did they fight? } \\
\text { They spent a long time away from } \\
\text { home. What was the idea to help them }\end{array}$ \\
\hline
\end{tabular}


Volume 16 - Número 1 - jan/jul de 2021

\begin{tabular}{|c|c|c|c|}
\hline $\begin{array}{l}\text { constitutivas do } \\
\text { gênero } \\
\text { discursivo. }\end{array}$ & & & $\begin{array}{l}\text { communicate? } \\
\text { What's the author's opinion about the } \\
\text { messages? }\end{array}$ \\
\hline \multicolumn{4}{|l|}{ Pós-leitura } \\
\hline $\begin{array}{l}\text { 4) Apreciação } \\
\text { crítica da } \\
\text { abordagem do } \\
\text { tema e } \\
\text { percepção de } \\
\text { relações } \\
\text { dialógicas que o } \\
\text { exemplar do } \\
\text { gênero } \\
\text { discursivo } \\
\text { estabelece }\end{array}$ & $\begin{array}{l}\text { - Avaliação do } \\
\text { conteúdo do texto } \\
\text { - Inferências }\end{array}$ & $\begin{array}{l}\text { - Apreciação das relações } \\
\text { estabelecidas com os } \\
\text { hiperlinks das notícias e } \\
\text { reportagens, com as } \\
\text { sugestões e com as tags. }\end{array}$ & $\begin{array}{l}\text { Você acha que as informações } \\
\text { foram de interesse para o público } \\
\text { atual? } \\
\text { - Em que medida essa reportagem se } \\
\text { conecta com a situação de pandemia } \\
\text { na atualidade? } \\
\text { - Você acha que seria possível contar } \\
\text { essa história sem fazer conexão com } \\
\text { a situação atual? }\end{array}$ \\
\hline
\end{tabular}

Fonte: Elaborado para esta pesquisa, a partir dos autores mencionados.

Para o primeiro procedimento (Pré-leitura), solicita-se que os alunos discutam com que frequência se comunicam por vídeo com outras pessoas a fim de fazer um levantamento sobre seus conhecimentos do tema da reportagem. Outros questionamentos buscam o conhecimento sobre gênero discursivo. Esse primeiro contato com a primeira tela da reportagem deve ser suficiente para os alunos inferirem que o texto aborda algo sobre a comunicação por vídeo. Observa-se que a ativação do conhecimento prévio não depende apenas do vocabulário na língua inglesa, mas também dos esquemas mentais que os alunos têm a respeito do tópico bem como do gênero discursivo. A discussão deve ser feita com a mediação do professor, sendo que nesse momento é pertinente que algumas curiosidades sejam anotadas como objetivos de leitura detalhada do texto.

$\mathrm{O}$ acesso à reportagem pode ser feito por meio de diversos recursos digitais, como $q r$ codes, encurtamento de links, criação de lista de transmissão no whatsapp. Ao acessar essa reportagem, os alunos devem observar os aspectos e recursos multissemióticos que integram ou não o texto principal. Há dois recursos que merecem destaque: o vídeo no início da reportagem, que é parte integrante do texto, e a opção de deixar comentários, que não é parte integrante do texto.

Ao assistir ao vídeo, deve-se esclarecer que o objetivo não é entender tudo do que está sendo falado, o que também é válido para a leitura, pois não é esperado um entendimento detalhado nessa primeira etapa, mas sim a compreensão geral do que está sendo dito/lido. Após assistir ao vídeo, deverão discutir as perguntas motivadoras apresentadas no quadro 3 e estabelecer hipóteses que poderão ou não ser confirmadas com a leitura do texto completo. A partir da observação das imagens contidas no vídeo, independente da compreensão oral, espera-se que os alunos percebam que são militares e que o vídeo é bastante antigo.

Concomitantemente, os alunos efetuam a leitura do título, do subtítulo e da legenda do vídeo. Curiosidades sobre se a reportagem abordou algum aspecto do tema ou sobre informações ainda não compreendidas na íntegra devem ser anotadas como objetivos de uma primeira leitura rápida. Espera-se que os alunos levantem hipóteses sobre o que a reportagem aborda, transformando essas hipóteses em objetivos de leitura do próprio aluno. Algo como: vou ler a reportagem para ver o que ela explica sobre... Espera-se estimular a curiosidade e sinalizar explicitamente para os alunos que essa geração de objetivos pode ser sempre feita ao ler outros textos. Ademais, é pertinente destacar o apoio fornecido pelas palavras cognatas, palavras já conhecidas e pelos recursos gráficos. O dicionário não deve ser usado nessa etapa. Para responder a esses objetivos de leitura, não é necessário a leitura detalhada do texto completo, mas apenas uma leitura 'por cima' (skimming) a fim de verificar o assunto geral e 
Volume 16 - Número 1 - jan/jul de 2021

identificar os trechos nos quais as hipóteses e questionamentos elaborados pelos alunos podem ser (des)confirmados. Durante todo o processo de leitura, a maneira como os alunos podem abordar o texto deve ser-lhes explicitada, a fim de que compreendam as estratégias metacognitivamente.

Para a leitura detalhada, o professor deve fazer algumas perguntas que incidam sobre as ideias principais do texto, buscando contribuir para uma compreensão geral que permita uma síntese coerente do conteúdo. A complexidade das perguntas dependerá do nível dos alunos, sendo, assim, é indispensável o planejamento do professor para cada realidade de sala de aula. Nesse procedimento, optou-se por propor as perguntas em inglês, pois o vocabulário presente nas perguntas pode contribuir para a identificação das informações no texto. Quanto ao ensino das estratégias, sugere-se explicitar aos alunos que não leiam o texto todo com a mesma atenção e velocidade, mas sim que saltem para as partes nas quais podem encontrar as respostas para as perguntas.

No último procedimento, a partir da identificação dos elementos constitutivos desse gênero discursivo e reconhecumento diversos recursos multissemióticos que integram essa reportagem, em especial o vídeo, é relevante questionar os alunos para que estabeleçam conexão do fato histórico resgatado pela reportagem com o contexto atual.

\section{Conclusão}

A partir dos diálogos teóricos estabelecidos nesta pesquisa, conclui-se pela viabilidade de desenvolver um trabalho voltado à leitura de reportagens veiculadas pela internet no ensino-aprendizagem da língua inglesa no $9^{\circ}$ ano do Ensino Fundamental e Ensino Médio. A discussão teórica mostrou como a concepção bakhtiana de linguagem e de gêneros discursivos pode articular-se à perspectiva sociocognitiva de leitura e a propostas de ensino de estratégias metacognitivas de leitura em língua inglesa. Foi possível sugerir procedimentos e estratégias que também contemplam as habilidades de leitura propostas pela BNCC (BRASIL, 2018) para o ensino de língua inglesa. Com a mediação do professor e a prática dessas estratégias, espera-se que os alunos incorporem essas estratégias habilidades de leitura que levarão para situações de leitura fora da sala de aula.

As reportagens veiculadas on line apresentam muitos recursos multimiádicos, incluindo hiperlinks que direcionam a outras fontes de informação. Ficou claro que é essencial sensibilizar os alunos com relação aos elementos multissemióticos que são parte integrante da reportagem e aos que não são, como publicidade e vídeos que não fazem parte do texto principal. Constituem-se rico material para atividades didáticas de leitura sobre temas atuais e conectados com a realidade de professores e alunos.

O quadro 1 proposto oferece uma ampla possibilidade de construção de atividades de leitura de reportagens nas aulas de língua inglesa, a partir de material autêntico, com o uso de tecnologias, a partir de fundamentação teórica. Não deve ser encarado pelo professor como uma sequência rígida, mas sim como um subsídio teórico e prático para julgar quais aspectos ou procedimentos de leitura merecem mais ou menos atenção a depender do tema, do conteúdo, dos objetivos de leitura, da dificuldade do texto e das necessidades e interesses dos alunos. Ele poderá ser ampliado ou adaptado ou ter alguns aspectos modificados quando for executado em salas de aulas. Na perspectiva sócio-histórica e dialógica em que esta pesquisa se fundamentou, não se espera realmente que seja rígido e permanentemente aplicado em todas as salas de aula de $9^{\circ}$ ano e de Ensino Médio. Espera-se, sempre, que professores e alunos expressem suas percepções e reflitam sobre as ações de leitura, reformulando os aspectos da proposta que se mostrarem necessários em cada contexto. 
Volume 16 - Número 1 - jan/jul de 2021

\section{Referências}

AFFLERBACH, Peter; PEARSON, P. D.; SCOTT, G. P. Clarifying differences between reading skills and reading strategies. The Reading Teacher, v. 61, n. 5, 2008, p. $364-373$. BAKHTIN, M. Os gêneros do discurso. In: BAKHTIN, M. Estética da Criação Verbal. Tradução de Paulo Bezerra. 6 ed. São Paulo: WWF Martins Fontes, 2011.

BRAIT, Beth. O texto nas reflexões de Bakhtin e do Círculo. In: BATISTA, R. de O. (Org.). O texto e seus conceitos. São Paulo: Parábola, 2016. p. 13-30.

BRASIL. Base Nacional Comum Curricular (BNCC). Brasília: MEC. 2018. Disponível em: http://basenacionalcomum.mec.gov.br/images/BNCC_EI_EF_110518_versaofinal_site.pdf > BRITISH COUNCIL. São Paulo, 2015. O ensino de inglês na Educação Pública Brasileira. Dísponivel em:

https://www.britishcouncil.org.br/sites/default/files/estudo_oensinodoinglesnaeducacaopublic abrasileira.pdf. Acesso em: 07 mai. 2019.

CARREL, Patricia L. Can reading strategies successfully be taught?. The Language

Teacher. v. 22, n.3, mar 1998. Disponível em: <https://jalt-publications.org/tlt/issues/199803_22.3>. Acesso em 30 ago. 2020.

COIMBRA, Oswaldo. O texto da reportagem impressa: um curso sobre sua estrutura. São Paulo: Ática, 2004.

DIONÍSIO, Ângela P. Gêneros multimodais e multiletramento. In: KARWOSKI, Acir M.; GAYDECZKA, Beatriz, BRITO, Karim S. (Org.). Gêneros textuais: reflexões e ensino. Palmas-PR: Kaygangue, 2005. p. 159-177.

DONNINI, Livia; PLATERO, Luciana; WEIGEL, Adriana. Ensino de Língua Inglesa. São Paulo: Cengage Learning, 2013.

FALKENBACH, Luciana I. S.; FONTANA, Niura M. Writing for life: materials might make a difference. In: BELT Brazilian English Language Teaching Journal, Porto Alegre, v.7, n.1, p. 44-63, 2016.

FARIA, Maria A. A leitura do jornal e do fotojornalismo. In: MARINHO, M. (Org.). Ler e navegar: espaços e percursos da leitura. Campinas: Mercado de Letras: Associação de Leitura do Brasil, 2001. p. 215-236.

FIORIN, José L. Introdução ao Pensamento de Bakhtin. São Paulo: Ática, 2011. GERVAI, Solange M. S. Reflexões sobre o ensino de língua estrangeira na escola pública brasileira. In: Revista Intercâmbio, São Paulo v.27, n. 1, p.184-194, 2018. Disponível em: $<$ https://revistas.pucsp.br/index.php/intercambio/article/view/36661>. Acesso em: 21 mai. 2019.

KOCH, Ingedore G. V. A construção sociocognitiva da referência. In: MIRANDA, N. S.; LAGE, Nilson. A reportagem: teoria e técnica de entrevista e pesquisa. Rio de Janeiro/São Paulo: Distribuidora Record de Serviços de Imprensa, 2001.

LAKATOS, Eva M.; MARCONI, Marina de A. Fundamentos da Metodologia Científica. 3.ed. rev. e ampl. São Paulo: Atlas, 1991.

LOPES-ROSSI, Maria A. G. Sequência didática para leitura de reportagem. In: BARROS, Eliana M. D. de; STRIQUER, Marilucia dos S. D.; STORTO, Letícia J. (Org.). Propostas didáticas para o ensino da Língua Portuguesa. 1. ed. Campinas: Pontes, 2018, v. 1, p. 71 90 .

MACHADO, I. Gêneros Discursivos. In: BRAIT, B. (org.) Bakhtin: Conceitos Chave. São Paulo: Contexto, 2005, p. 151-166.

MARCUSCHI, Luiz A. Exercícios de compreensão ou copiação nos manuais de ensino de língua? In: LAJOLO, Marisa. (Org.). Em Aberto. Brasília, ano 16, n. 69, jan./mar. 1996. p. 64-82. 
Volume 16 - Número 1 - jan/jul de 2021

MARCUSCHI, Luiz A. Luiz A. Produção textual, análise de gênero e compreensão. São Paulo: Parábola, 2008.

MARTINS FILHO, Eduardo Lopes. Manual de redação e estilo O Estado de São Paulo. 3.ed. São Paulo, Moderna, 1997.

MKEOWN, Margaret G.; BECK, Isabel L.; BLAKE, Ronette G. K. Rethinking reading comprehension instruction: a comparison of instruction for strategies and content approaches. Reading Research Quarterly, v. 44, n. 3, 2009, p. 218 - 253.

MOKHTARI, Kouider; REICHARD, Carla A. Assessing students' metacognitive awareness of reading strategies. Journal of Educational Psychology. v. 94, n. 2, 2002, p. 249-259.

NOBLAT, Ricardo. A arte de fazer um jornal diário. 7ed. São Paulo: Contexto, 2008. O GLOBO. Manual de redação e estilo. Organizado e editado por Luiz Garcia. $28^{a}$ ed. São Paulo: Globo, 2003.

PONTES, Vanessa de F.; DAVEL, Marcos A. N. O inglês na educação básica: um desafio para o professor. In: Revista X, n. 10, v. 1, p. 102-117, 2016. Disponível em:

$<$ https://revistas.ufpr.br/revistax/article/view/32055/27931>. Acesso em: 21 mai. 2019

ROJO, Roxane; BARBOSA, Jacqueline P. Hipermodernidade, Multiletramentos e

Gêneros Discursivos. São Paulo: Parábola, 2015.

ROCHA-PINTO, Renata C. S. R. Leitura de notícias e reportagens de jornais online em inglês: uma proposta para os ensino Fundamental e Médio. Dissertação (Mestrado em Linguística Aplicada) - Universidade de Taubaté, Taubaté, 2020.

SANTORUM, Karen; SCHERER, Lílian C. O papel do ensino de estratégias para o desenvolvimento da leitura em segunda língua (L2). In: ReVEL. Vol. 6, n. 11, 2008.

SCALZO, Marília. Jornalismo de revista. São Paulo: Contexto, 2003.

SCRIVENER, Jim. Learning Teaching: The essential guide to English language teaching. 3.ed. Macmillan Education, 2011, p. 170 -191.

SINGHAL, Meena. Reading proficiency, reading strategies, metacognitive awareness and L2 reading. The reading matrix, v. 1, n. 1, abr. 1998.

SOUSA, Lucilene Bender de; GABRIEL, Rosângela. Fundamentos cognitivos para o ensino da leitura. Signo. V. 34, n. 57. Santa Cruz do Sul, p. 47-63, jul./dez. 2009. Disponível em < http://online.unisc.br/seer/index.php/signo/index.

TILIO, Rogério. Atividades de leitura em livros didáticos de inglês: PCN, letramento crítico e o panorama atual. RBLA, Belo Horizonte, 2012, vol.12, n.4, p.997-1025, sep. 2012.

Disponível em: $<$ http://www.scielo.br/scielo.php?pid=S1984-

63982012000400016\&script=sci_abstract\&tlng=pt $>$. Acesso em 21 mai. 2019.

VARGAS, Diego da S. Por uma visão cognitivista do processo de inferenciação em leitura.

Ciências \& Cognição, V. 20, n. 2, p. 313-330, 2015. Disponível em

$<$ http://www.cienciasecognicao.org $>$. Acesso em 21 mai 2019.

VIANA, Fernanda Leopoldina; CADIME, Irene; SANTOS, Sandra; BRANDÃO SARA;

RIBEIRO, IOLANDA·O ensino explícito da compreensão da leitura. Análise do impacto de um programa de intervenção. Revista Brasileira de Educação, Rio de Janeiro, v. 22, n. 71, p. 1-30, 2017. Disponível em: https://doi.org/10.1590/s1413-24782017227172. Acesso em: 15 jun. 2019.

WALLACE, Catherine. Reading. In: CARTER, Ronald; NUNAN, David. The Cambridge Guide to Teaching English to Speakers of Other Languages. Cambridge: Cambridge University Press, 2001.

WATKINS, Peter. Teaching and developing reading skills. Cambridge: Cambridge University Press, 2017. 